University of New Haven

University of

New Haven

Digital Commons@ New Haven

6-2014

\title{
Electrochemical-Mechanistic Model for Concrete Cover Cracking Due to Corrosion Initiated by Chloride Diffusion
}

\author{
Goli Nossoni \\ Manhattan College \\ Ronald S. Harichandran \\ University of New Haven, rharichandran@newhaven.edu
}

Follow this and additional works at: http://digitalcommons.newhaven.edu/civilengineering-facpubs Part of the Civil Engineering Commons

\section{Publisher Citation}

Nossoni, G., Harichandran, R. S. (2014). "Electrochemical-mechanistic model for concrete cover cracking due to corrosion initiated by chloride diffusion.” Journal of Materials in Civil Engineering, ASCE, 26(6). doi:10.1061/(ASCE)MT.1943-5533.0000470

\section{Comments}

This is the authors' accepted version of the article published in Journal of Materials in Civil Engineering. The version of record can be found in the ASCE library at http://dx.doi.org/10.1061/(ASCE)MT.1943-5533.0000470 


\title{
Electrochemical-Mechanistic Model for Concrete Cover Cracking due to Corrosion Initiated by Chloride Diffusion
}

\author{
G. Nossoni ${ }^{1}$ and R.S. Harichandran, ${ }^{2}$ F. ASCE
}

\begin{abstract}
A holistic electrochemical-mechanistic model of the corrosion of steel reinforcing bars inside concrete and the time to cracking of the concrete cover is presented. The model accounts for the diffusion of oxygen and moisture into the concrete and rust layers, the densification of rust due to confinement, the flow of rust into the concrete pores, the development of internal pressure due to rust build-up, and cracking of the concrete cover. The relationship between the corrosion current and the pressure build-up due to the corrosion products for different concrete cover thicknesses was calibrated through experiments using an accelerated corrosion test with an applied current. Results from finite element analysis with an inelastic smeared crack concrete model were used to calibrate a simple analytical model of the critical internal pressure required to cause cracking of the concrete cover. The various sub-models are linked together to predict the time for cracking of the concrete cover from the time of corrosion initiation. Results of parametric studies using the model indicate that the main factors that control the corrosion current and the time to cracking are the boundary condition, water/cement ratio and concrete cover.

\footnotetext{
${ }^{1}$ Assistant Professor, Department of Civil and Environmental Engineering, Manhattan College, Riverdale NY 10471

2 Previously Prof. \& Chair, Dept. of Civil and Envir. Engrg., Michigan State Univ., East Lansing MI 48824-1226. Currently Dean, Tagliatela College of Engineering, Univ. of New Haven, West Haven, CT 06516.
} 
Key word: Cathodic reaction, oxygen diffusion, limiting current, pressure loss, rust thickness, concrete cover cracking

\section{INTRODUCTION}

Reinforced concrete is one of the most common construction materials. High quality concrete is a very durable material and can remain maintenance free for many years when properly designed. Steel reinforcement is used to improve the tensile strength of concrete structures, and more generally their mechanical resistance. The high alkalinity of concrete can prevent the reinforcing steel from corroding within it; in other words steel is passive inside concrete. Depassivation of steel reinforcement embedded in concrete and the onset of active corrosion can arise due to two causes: carbonation of the concrete, or chloride diffusion. For pore solution which has a $\mathrm{pH}$ of about 13.5, corrosion will commence when the $\left[\mathrm{Cl}^{-}\right] /\left[\mathrm{OH}^{-}\right]$ratio reaches a threshold value. For synthetic concrete pore solution this ratio is about 0.6 (Mindess et al. 2003, Haussmann 1967), but the threshold values reported in literature vary from 0.3 to above 3 depending on many factors such as temperature, stress level, pitting potential, experimental conditions, and experiment methods (Alson et al. 2002, Ann and Song 2007). The depassivation condition and the time at which the chloride concentration reaches the threshold value have been the subjects of many investigations (Truc et al. 1999, Gowripalan, et al. 2000, Stanishn and Thomas 2001, Xi et al. 2000, Glass and Buenfield 1999) and the depassivation time can be predicted with good accuracy.

The corrosion process is very complex and modeling is often based on observation or speculation rather than a clear understanding of the physical and chemical processes involved (Palle 2002, Du et al. 2006). Considerable experimental data and semi-empirical models are available on the corrosion rate of steel in chloride-contaminated concrete (Liu 
1996, Newhouse and Weyers 1996, Newhouse 1993). However, to our knowledge no electrochemical-mechanistic model exists for the corrosion of steel reinforcement in concrete due to chloride diffusion and the subsequent cracking of the concrete cover

Corrosion of steel in concrete consists of two stages. The first stage is controlled by the anodic reaction and is very short despite having a high corrosion rate. In the second stage the current is limited by the cathodic reaction. This is the corrosion current often measured by researchers (Liu 1996). In this paper an electrochemical-mechanistic model is developed for the corrosion rate during the second stage based on a fundamental understanding of the electrochemical corrosion reaction and the effect of oxygen concentration on the cathodic reaction. The corrosion rate is then used to predict the time for cracking of the concrete cover due to corrosion. The cathodic control corrosion rate has been proposed for modeling the corrosion rate in carbonated concrete but has not been studied for corrosion due to chloride diffusion, although the corrosion reaction in both cases is similar (Huet et al. 2006, Liang et al. 2004).

The rust thickness is calculated and used to estimate the pressure applied to the concrete cover, accounting for the amount of rust products that flow into the concrete pores. The calculation of rust thickness as a function of corrosion current has not been studied extensively. An elasto-plastic concrete material model was used to calculate the pressure developed due to thickening of the rust layer. The critical pressure that causes the concrete cover to crack was calculated and calibrated with finite element analysis and experimental data. 


\section{CORROSION CURRENT MODELING}

The corrosion reaction can be described by two elementary anodic and cathodic reactions:

$$
\begin{aligned}
& \mathrm{Fe} \rightarrow \mathrm{Fe}^{++}+2 \mathrm{e}^{-} \\
& \mathrm{O}_{2}+2 \mathrm{H}_{2} \mathrm{O}+4 \mathrm{e}^{-} \rightarrow 4 \mathrm{OH}^{-}
\end{aligned}
$$

When there is no limitation of oxygen in the corroding system, the corrosion current will increase with increasing chloride concentration. However, even if oxygen is available, the corrosion current will reach the anodic limiting current because the rate of diffusion of corrosion products away from the anode is limited (Nossoni 2010). This limiting current is very high and cannot be reached for the corrosion of steel inside concrete. We assume that the oxygen reduction in the catholic reaction (Equation 2) controls the corrosion rate. To determine the availability of oxygen for the cathodic reduction reaction and for corrosion to continue we must determine the path for oxygen diffusion to the corrosion pit.

\section{Corrosion Scale}

Knowledge of the composition and structure of the corrosion products in concrete is necessary not only to estimate the corrosion expansion and pressure applied on the concrete cover, but also to estimate the corrosion rate based on the limiting current, diffusion of oxygen, and reduction of species inside and outside the pit. The structure of the pit and corrosion products depends on the aqueous phase of the pore solution, steel type, and pressure adjacent to the bar. In general, the composition of the expansive corrosion products may be expressed as $\left\{a \cdot \mathrm{Fe}(\mathrm{OH})_{2}+b . \mathrm{Fe}(\mathrm{OH})_{3}+c \cdot \mathrm{H}_{2} \mathrm{O}\right\}$ (Bhagava et al. 
2005), where $a, b$ and $c$ are variables that depend on the alkalinity of the pore water solution of the concrete, the oxygen supply, and the moisture content. For example, black rust $\left(\mathrm{Fe}_{2} \mathrm{O}_{3}\right)$ will form mostly in concrete immersed in deep water where the oxygen availability is low (Bazant 1997).

The model adopted herein for the corrosion scale is taken from the literature (Sarin et al. 2004, Jones 1992, Huet et al. 2004) and is shown in Figure 1. The corrosion scale consists of three layers: the inside part (core layer), the outer part (top layer), and a hard shell layer that separates these two layers (Sarin et al. 2004).

The core layer is generally a porous mass made up of small particles of different component phases. Fe(II) is expected to dominate the core part of the scale due to a lack of hydroxide ions. The wet outside region of the scale on top of the shell layer is the top layer. Since the top layer is exposed to water and air in the concrete pores, the ferrous hydroxide is rapidly oxidized to the ferric components $\mathrm{Fe}(\mathrm{OH})_{3}$ and $\mathrm{Fe}(\mathrm{OH})_{3}+3 \mathrm{H}_{2} \mathrm{O}$, and consequently the concentration of Fe (III) is expected to be higher than in the core layer. The top layer is saturated with the concrete pore solution. Around the outside of the top layer particles are loosely held and can be easily transferred to the concrete pore water under the pressure that is produced (Sarin et al. 2004).

$\mathrm{Fe}(\mathrm{II})$ products are more conductive than $\mathrm{Fe}(\mathrm{III})$ products and can transfer electrons outside the core layer. We assume that the cathodic reaction takes place in the top layer where both oxygen and electrons are available.

\section{Corrosion Current}

Corrosion of steel in an alkaline environment starts when the chloride concentration reaches a certain threshold value. Most existing models treat corrosion as a steady state 
phenomenon, although it is known that the corrosion rate varies with change in temperature, chloride content, and corrosion level (Pantaopoulou et al. 2001, Bhargava et al. 2005, El Maaddawy and Soudki 2007). No comprehensive model is available to take all of these factors into account and only an electrochemical-mechanistic model that accounts for most of these factors can predict the long-term behavior of concrete accurately.

Initially, the rate of corrosion will depend on the chloride concentration and the rate of the anodic reaction. Shortly thereafter, as the corrosion becomes more severe and the rust layers build up, the corrosion rate will be controlled by the cathodic reaction and the availability of oxygen at the cathode.

The limiting current at any time can be calculated through:

$$
i_{\lim }=n_{O_{2}} \cdot F \cdot j_{o_{2}, u s e d}
$$

where $j_{O_{2}, \text { used }}$ is the flux of the oxygen consumed at the cathode, $n_{\mathrm{O}_{2}}$ is 4 for the reduction of oxygen in the corrosion reaction, and $F$ is Faraday's constant.

Figure 2 shows a simplified model of the different stages of oxygen diffusion to the anode. The flux of oxygen to the steel bar can be divided into three stages. In the first stage oxygen diffuses through the concrete cover and will follow Fick's Second Law (Castellote et al. 2001):

$$
\frac{\partial C_{O_{2}}}{\partial t}=D_{0} \frac{\partial^{2} C_{O_{2}}}{\partial x^{2}}
$$

where $C_{\mathrm{O}_{2}}$ is the oxygen concentration, and $D_{O}$ is the coefficient for diffusion of oxygen into the concrete cover. Only the dissolved oxygen can be used in the cathodic reaction. It 
is assumed that the dissolved oxygen is in thermodynamic equilibrium with the oxygen partial pressure in the gaseous phase, and according to Henry's Law

$$
C_{O_{2}, l, i n}=C_{O 2, g, i n} \frac{R T}{K_{H}}
$$

where $C_{O_{2}, l, i n}$ is the dissolved oxygen concentration, $C_{O_{2}, g, \text { in }}$ is the concentration of oxygen gas in the concrete adjacent to the bar, $T$ is the temperature in degrees Kelvin, and $K_{H}$ is a constant. The degree of concrete saturation is in equilibrium with the outside relative humidity. The semi-empirical equations proposed by Bazant and Thongutha $(1978,1979)$ were used to calculate the water content of the concrete.

$C_{O_{2}, l, i n}$ diffuses across the top layer of the rust scale which is assumed to be fully saturated. The top layer consumes some of the oxygen in the secondary nonelectrochemical reaction, in which Fe(II) is oxidized to Fe(III):

$$
\begin{aligned}
& 4 \mathrm{Fe}(\mathrm{OH})_{2}+\mathrm{H}_{2} \mathrm{O}+\mathrm{O}_{2} \longrightarrow 4 \mathrm{Fe}(\mathrm{OH})_{3} \\
& 4 \mathrm{Fe}(\mathrm{OH})_{2}+\frac{1}{2} \mathrm{O}_{2} \longrightarrow 2 \gamma-4 \mathrm{FeOOH}+\mathrm{H}_{2} \mathrm{O}
\end{aligned}
$$

Assuming that the top layer is a homogeneous porous medium, Fick's First Law can be used to predict the flux of the diffused oxygen through the rust layer:

$$
j_{O_{2}, \text { used }}=\left(D_{o, r} \frac{\partial C_{O_{2}}}{\partial x}\right)
$$

where $D_{O, r}$ is the coefficient for diffusion of oxygen into the rust layer, and can be calculated from the general equation for diffusion in porous media (Martys 1994). 
The limiting current occurs when $C_{\mathrm{O}_{2}}$ at the bar lever is zero, and all the diffused oxygen is consumed. The limiting oxygen flux can be estimated from

$$
\frac{\partial C}{\partial x}=\frac{C_{O_{2}, l, \text { in }}-C_{O_{2}, \text { consumed }}}{\delta_{2}}
$$

where $\delta_{2}$ is the top rust layer thickness.

The final limiting current will be

$$
i_{\text {limit }}=n_{O_{2}} \cdot f \cdot D_{o, r} \cdot\left(\frac{C_{O_{2}, l, \text { in }}-C_{O_{2}, \text { consumed }}}{\delta_{2}}\right)
$$

where $C_{O_{2} \text {,consuned }}$ is the loss in oxygen concentration due to consumption of oxygen for the secondary reaction presented in Equation 6 in the top layer.

According to Faraday's Law, the flux of the $\mathrm{Fe}^{2+}$ produced will be

$$
j_{\mathrm{Fe}(\mathrm{OH})_{2}}=\frac{i_{\text {corr }}}{n_{\mathrm{Fe}} \cdot F}
$$

Assuming that Equation 6 dominates the secondary reaction:

$$
j_{\mathrm{Fe}(\mathrm{OH})_{3}}=k_{r} J_{\mathrm{Fe}(\mathrm{OH})_{2}}
$$

$k_{r}$ is the fraction of $\mathrm{Fe}(\mathrm{OH})_{2}$ that is transformed to $\mathrm{Fe}(\mathrm{OH})_{3}$ in the secondary reaction and needs to be determined experimentally or obtained from the literature. $k_{r}$ can be assumed to be 1.0 in air since $\mathrm{Fe}(\mathrm{OH})_{2}$ is not a stable product when sufficient oxygen is available, and for corrosion of steel in concrete it can vary from 1.0 to less than 0.5 depending on the availability of oxygen. A parametric study was done to evaluate the effect of this factor on the limiting current. In this paper $k_{r}$ is assumed to be 0.5 . This value does not 
affect the results considerably since the rust thickness was calibrated using experimental test data.

$C_{O_{2}, \text { consumed }}$ can be calculated from Equation 12 since the flux of the consumed oxygen is four times smaller than the flux of the $\mathrm{Fe}(\mathrm{OH})_{3}$ produced (see Equation 6). Thus,

$$
\frac{d C_{\mathrm{O}_{2}, \text { consumed }}}{d t}=\frac{j_{\mathrm{Fe}(\mathrm{OH})_{3}}}{4 . \delta_{2}}
$$

Assuming that the density of the porous core and top layer is a function of pressure and 3.75 and 4.20 times smaller than the density of steel, respectively (Bhagava et al. 2005) the rate of build-up of corrosion products is:

$$
\begin{gathered}
\frac{d \delta_{1}}{d t}=\frac{j_{\mathrm{Fe}(\mathrm{OH})_{2}} \cdot A_{\mathrm{Fe}(\mathrm{OH})_{2}}}{\rho_{\mathrm{Fe}(\mathrm{OH})_{2}}}=\frac{3 \cdot 75\left(j_{\mathrm{Fe}(\mathrm{OH})_{2}}-j_{\mathrm{Fe}(\mathrm{OH})_{3}}\right) \cdot A_{\mathrm{Fe}(\mathrm{OH})_{2}}}{\rho_{\mathrm{Fe}} \cdot K_{\mathrm{P}}} \\
\frac{d \delta_{2}}{d t}=\frac{j_{\mathrm{Fe}(\mathrm{OH})_{3}} \cdot A_{\mathrm{Fe}(\mathrm{OH})_{3}}}{\rho_{\mathrm{Fe}(\mathrm{OH})_{3}}}=\frac{4 \cdot 20 j_{\mathrm{Fe}(\mathrm{OH})_{2}} \cdot A_{\mathrm{Fe}(\mathrm{OH})_{3}}}{\rho_{\mathrm{Fe}} \cdot K_{\mathrm{P}}}
\end{gathered}
$$

where $\rho_{\mathrm{Fe}}, \rho_{\mathrm{Fe}(\mathrm{OH}) 2}$ and $\rho_{\mathrm{Fe}(\mathrm{OH}) 3}$ are the densities of iron, $\mathrm{Fe}(\mathrm{OH})_{2}$ and $\mathrm{Fe}(\mathrm{OH})_{3}$, respectively. $K_{P}$ is a correction factor that accounts for pressure dependency of the density of the corrosion products. $K_{P}$ was calibrated using experimental test result. $K_{P}$ is an important parameter that affects the pressure applied to the concrete cover, the rust thickness that affects the oxygen diffusion (Figure 1), and the diffusion coefficient of oxygen in the rust. 


\section{MECHANISTIC MODEL OF CONCRETE COVER CRACKING}

\section{Development of Pressure}

Concrete surrounding the rebar will be subjected to an internal radial pressure due to the expansive corrosion products modeled using Equations 14 and 15. It is assumed that the corrosion occurs uniformly around the steel bar. The radial strain is:

$$
\varepsilon_{r}=\frac{d u}{d r}+v \cdot \frac{u}{r}
$$

The rates of radial and circumferential strain due to thickening of the rust layer are:

$$
\begin{array}{r}
\frac{d \varepsilon_{r}}{d t}=\frac{d\left(\delta_{1}+\left(\delta_{2}-\delta_{0}\right)-\delta_{3}\right)}{d t . \delta}+v \cdot \frac{d \varepsilon_{\theta}}{d t} \\
\frac{d \varepsilon_{\theta}}{d t}=2 . \frac{d\left(\delta_{1}+\left(\delta_{2}-\delta_{0}\right)-\delta_{3}\right)}{d_{b a r} . d t}
\end{array}
$$

where $\delta_{3}$ is the reduction in diameter of the steel bar due to corrosion and can be calculated using Faraday's Law, $\delta_{0}$ is the loss in rust layer thickness due to diffusion of rust products into the concrete, and $\delta_{1}$ and $\delta_{2}$ are the thicknesses of the porous core and top layer of rust. The rate of reduction in bar diameter is given by

$$
\frac{d \delta_{3}}{d t}=\frac{j_{F e}}{\rho_{F e}}
$$

where $j_{F e}$ is the flux of Fe into the system and $\rho_{F e}$ is the density of iron.

The rate of pressure growth at the steel surface due to thickening of the rust layer was calculated using the nonlinear concrete constitutive relation given by (MacGrego 1997): 


$$
P_{n e t}=\frac{2 P_{c r i}\left(\frac{\varepsilon_{\theta}}{\varepsilon_{0}}\right)}{1+\left(\frac{\varepsilon_{\theta}}{\varepsilon_{0}}\right)^{2}}
$$

where $P_{c r i}$ is the critical pressure that causes the concrete to crack. $P_{\text {net }}$ is net pressure on the concrete cover from corrosion products, $\varepsilon_{\theta}$ is the strain obtained from Equation 18, and $\varepsilon_{0}$ can be calculated using

$$
\varepsilon_{0}=\frac{1.75 \cdot f_{t}}{E_{c o n}}
$$

The accuracy of Equation 20 was verified using finite element analysis with a nonlinear concrete material model (Caré et al. 2008).

The pressure is assumed to be uniform around the bar. The pressure will cause some amount of corrosion products (mainly red rust in the top layer) to flow into the concrete pores surrounding the steel rebar before the concrete cracks. Some researchers assumed a "gap" of 10 to $20 \mu \mathrm{m}$ around the steel bar to account for the slower build-up of pressure (Du et al. 2006, El Maaddawy and Soudki 2007, El Maaddawy et al. 2006), and the size of this "gap" was calibrated based on experimental test results. We explicitly model the flow of rust products into the concrete pores.

\section{Calculation of $\delta_{0}$}

The amount of accumulate pressure around the bar will decrease due to the flow of rust products from the top layer into the concrete pores, thereby increasing the time for the concrete to crack.

Conservation of mass yields: 


$$
\left(j_{\mathrm{Fe}(\mathrm{OH})_{3}}+d j_{\mathrm{Fe}(\mathrm{OH})_{3}}-j_{\mathrm{Fe}(\mathrm{OH})_{3}}\right) A=\frac{\partial w}{\partial t}\left(V_{t}\right)
$$

where $A$ is the cross sectional area of corrosion pit, $j_{\mathrm{Fe}(\mathrm{OH}) 3}$ is the flux of the top layer products in concrete pores, $w$ is the mass of $\mathrm{Fe}(\mathrm{OH})_{3}$ per volume of concrete, and $V_{t}$ is the total volume of concrete. Expressing the saturation of rust as $s=w / n$, where $n$ is the porosity, and since $V_{t}=A d x$, Equation 22 can be expressed as

$$
\frac{d j_{F e(O H)_{3}}}{d x}=n \frac{\partial s}{\partial t}
$$

Assuming that the flow of rust suspension is similar to the flow of water, Darcy's equation can be used to relate the pressure to flow:

$$
\frac{d}{d x}\left(k_{c} \frac{d p}{d x}\right)=n \frac{\partial s}{\partial t}
$$

where $p$ is the pore pressure and $k_{c}$ is the conductivity of the colloidal solution of $\mathrm{Fe}(\mathrm{OH})_{3}$ inside the concrete.

The Van Genuchten equation developed for the flow of liquid and gas in porous media relates pore pressure and saturation (Monlouis et al. 2007, Van Genuchten 1980):

$$
p=M\left(s^{\frac{1}{m}}-1\right)^{1-m}
$$

where $M$ and $m$ are empirical parameters for concrete (Coussy et al. 2004). The conductivity of the colloidal suspension of rust products in water can be related to the conductivity of water through:

$$
k_{c}=\frac{K_{k}}{\eta_{r}}
$$


where $K_{k}$ is conductivity and $\eta_{r}$ is the density of water relative to the density of colloidal suspension of rust products in water.

Equations 24,25 and 26 constitute the model for the flow of rust products into the concrete pores. The internal pressure can be computed through an incremental time step procedure. After corrosion starts, the pressure begins to accumulate. This pressure pushes some amount of the corrosion products produced in the top layer (mostly red rust) into the concrete pores and this reduces the pressure around the bar. When the pressure of the rust suspension inside the concrete pores exceeds the tensile strength of the concrete, the concrete will crack.

\section{Critical Pressure}

Cracking of the concrete cover is highly dependent on the ratio of the concrete cover to reinforcing bar diameter defined as

$$
k=D / d
$$

where $D$ is the diameter of the concrete cylinder and $d$ is the diameter of the steel bar.

An empirical model from the literature was adopted in this study and validated and calibrated using finite element analysis performed with the ABAQUS commercial software. According to the empirical model, for $k<5$ fracture occurs when the mean value of the circumferential stress reaches the tensile strength of the concrete:

$$
\bar{\sigma}_{t}=\sigma_{m}
$$

Equation 28 implies that cracking occurs when the net pressure on the concrete cover is 


$$
p_{\text {in }}-p_{\text {out }}=(k-1) \cdot \sigma_{m}
$$

where $p_{\text {in }}$ is the pressure that the rust layer applies to the concrete cover and $p_{\text {out }}$ is the pressure lost due to flow of rust from the top layer into concrete pores. However, for $k>$ 5 the first crack opens before the circumferential stress reaches the tensile strength of the concrete; i.e., when

$$
\begin{gathered}
\bar{\sigma}_{t}=\alpha \sigma_{m} \\
p_{\text {in }}-p_{\text {out }}=(\alpha k) \cdot \sigma_{m}
\end{gathered}
$$

where $\alpha$ is a factor established in the literature through experiments and $\sigma_{m}$ is the splitting tensile strength of concrete. In this study, finite element analysis was used to calibrate the $\alpha$ factor and yielded $\alpha=0.72$, which compares well with the value of $\alpha=$ 0.8 reported by Shah and Swart (1987).

\section{Finite Element Analysis}

Since corrosion causes radial expansion, a 2-D plane strain model can be used to study the mechanical behavior of concrete. Three different $k$ ratios of 3,4 and 6 were used in the model to match the $k$ ratios of experimental specimens described later. Figure 3 shows the geometry of the FE models. Due to symmetry of the model, only half of each specimen was modeled and appropriate boundary conditions were applied. The concrete damage plasticity model was used to model concrete (ABAQUS 6.4). When the rebars corrode, the corroded steel swells to about 2 to 6 times of its initial volume (Mehta 1993). The expansion of the rust products will apply internal pressure to the concrete cover. This expansion causes the concrete cover to crack and eventually spall. The objective of the FE analysis was to find the pressure-displacement relationship and calibrate the $\alpha$ 
coefficient in Equations 30 and 31. The reinforcing steel was replaced by a uniform radially outward pressure that was applied in increments over time steps until the concrete cover cracked. Since the ABAQUS concrete plasticity model cannot account for the opening of a large crack, the analysis terminates when the crack opens. The amount of pressure at this time step was considered to be the critical pressure, and the $\alpha$ factor was calibrated using this pressure. Figure 3 shows the rust thickens and applied pressure for both model and FEM for $\alpha=0.72$.

\section{Calibration of the Model}

The factor $K_{P}$ that accounts for densification of rust with pressure needs to be calibrated experimentally. To calibrate $K_{P}$, the model was used to predict the rust thickness and cracking time for accelerated corrosion experiments using the applied constant current density of $0.0045 \mathrm{~A} / \mathrm{cm}^{2}$. The goal was to establish a single representative value of $K_{P}$ for different $k$ values using experimental data of the time to cracking. After calibration, the rust thicknesses obtained from the experimental test and the model were compared to establish the accuracy of the model.

\section{EXPERIMENTAL INVESTIGATION}

Experiments were conducted using an accelerated corrosion test with an applied current to measure the growth of rust thickness. The test was conducted in an environment in which all the applied current was consumed in corroding the steel bar (Nossoni et al. 2011). The rust thickness was measured under the microscope using photographs taken at different time intervals. The time to cracking was obtained as a function of the measured rust thickness. 


\section{Specimen Preparation}

A normal concrete mix with Portland cement Type I, a maximum coarse aggregate size of $9.5 \mathrm{~mm}\left(3 / 8^{\prime \prime}\right)$, and a water-cement ratio of 0.41 was used to prepare the specimens. The maximum aggregate size was chosen to be small due to the small dimensions of the specimens. No chloride was added to the mix. The concrete had a 28day compressive strength of $57.2 \mathrm{MPa}(8,300 \mathrm{psi})$. The specimens were cast in small cylindrical shapes having a thickness of $25 \mathrm{~mm}$ (1-inch) with a \#4 carbon steel bar in the center to serve as an anode. The diameter of the cylinder was chosen to yield $k$ ratios of 3 , 4, and 6. Figure 4 shows the schematic of the test specimens.

Three \#1 carbon steel wires to be used as cathodes were placed equi-distant from each other and the anode, close to the outer edge of each specimen. For each specimen size, tests were conducted on triplicates. The goal of the experiments was to obtain a single representative $K_{P}$ value for all specimen sizes, and the ratio of the maximum aggregate size to concrete cover being large was not expected to introduce much error in the final calibration results.

A certain amount of chloride ions is needed even in the accelerated corrosion test so that all the applied current is consumed in oxidizing the steel bar (Caré et al. 2008, Nossoni et al. 2011, Austin et al. 2008). Therefore, before testing the specimens were soaked in $3.5 \% \mathrm{NaCl}$ by weight for one week for the smallest specimens having a concrete cover of $10 \mathrm{~mm}$, and more than one month for the largest specimens. This allowed the chloride concentration at the bar surface to be sufficient so that all the applied current oxidized the steel. The specimens were immersed in the salt solution after 28 days of curing. 
Before testing, each specimen's top surface was polished with grade 400 sand paper and then cleaned with methanol to expose the steel bars (anode and cathodes). The bottom surface was coated with epoxy to prevent the corrosion products from escaping out of the concrete. Also, the surfaces of the steel bars that were not embedded inside the concrete and were needed for the electrical connection were coated with epoxy to prevent any corrosion in this part and to prevent any variation in current density due to change in electrode surface area.

\section{Accelerated Corrosion Test and Test Set up}

The accelerated corrosion test consisted of applying a current so that the reinforcing bar served as an anode and corroded in a short time. Figure 4 shows the test set up for the accelerated corrosion test under the microscope. A power supply was used to apply a constant direct current between the anode and cathodes. The applied current was limited to $0.05 \mathrm{~A}$ yielding a current density of $0.0045 \mathrm{~A} / \mathrm{cm}^{2}$ at the anode. The high current density was not expected to be problematic because the test environment assured that all the applied current would be consumed in corroding the steel bar (Nossoni et al. 2011).

An optical microscope with a magnification of 25 to 100 was used to capture images of the concrete and steel interface to measure the rust layer thickness. After immersion in salt water, the surfaces of specimens were dried and the test was conducted in a dry condition. The dry condition prevented any escape of rust products outside the concrete during the test. Initial images were taken before the test began. When the current was applied, images were captured at 15 to 30 minute intervals depending on the size of specimens. 
Before capturing images, the test was stopped temporarily, and each specimen's surface was polished again with sand paper and cleaned with methanol. Methanol was used to minimize damage to the rust layer during the polishing stage since it has minimal reaction with rust. The test was continued until cracking initiated in the concrete and the rust thickness was measured. Although the main purpose of the test was to estimate the rust thickness and time to concrete cracking as a function of the applied current, the test was continued even after the concrete cracked.

\section{Measurement of Rust Thickness}

Observation of specimens subjected to the accelerated corrosion test under the optical microscope allowed measurement of the rate of rust thickness build-up as a function of applied current and time. Figure 6 shows that during the first 15 minutes of the test no identifiable rust layer was observed. It is likely that during this period the rust mostly diffused into the micro-pores around the steel bar.

After about 30 minutes the rust layer became visible, mostly around the areas where some rust had already accumulated in the pores. The rust thickness was not uniform around the steel bar and the areas surrounding the micro-pores had a thicker rust layer than other areas.

Figure 7 shows that the average rust thickness had an approximately linear relationship with time in this experiment since the corrosion current was constant, but this may not be the case in real corrosion where the corrosion current may vary with time. For the specimens with $k=3$, it took 45 to 60 minutes for the first crack to appear, at which time the average rust thickness around the steel bar was between 00.012 and $0.0142 \mathrm{~mm}$ ( 0.00046 and 0.00056 in.). For specimens with $k=4$ it took between 65 to 80 minutes for 
the first crack to appear, at which time the average rust thickness around the bar was between 0.014 and $0.021 \mathrm{~mm}(0.00057$ and 0.00082 in.). For specimens with $k=6$ it took between 95 to 125 minutes for the first crack to appear, at which time the average rust thickness was between 0.023 and $0.033 \mathrm{~mm}$ (0.0009 and $0.0013 \mathrm{in}$.). As shown in Figure 7 , using $K_{p}=1.56$ in the model yields predictions of the cracking time that match well with the cracking times observed in the experiments for all three $k$ values.

\section{PARAMETRIC STUDIES}

After calibrating the corrosion model using the experimental test results, the model was used to calculate the corrosion current and the time to cracking of the concrete cover for typical structural elements. The effect of different boundary conditions, concrete cover thicknesses, and concrete quality (represented by the water/cement ratio) were assessed.

The chloride on the concrete surface can originate from various sources. Bridge structural components can be categorized as superstructure components (boundary condition type 1), splash zone components (boundary condition type 2), and submerged components (boundary condition type 3 ). For submerged components (BC3), there is a constant supply of water and chloride to the surface of the concrete. However, corrosion of steel is often limited by the lack of oxygen dissolved in the water. Components in the splash zone (BC2) have a good supply of both oxygen and chloride, and these components experience the greatest corrosion. For superstructure components $(\mathrm{BC} 1)$, the chloride supply can limit the initiation of corrosion since it is supplied mainly by deicing salts. 
Three different concrete cover thicknesses of 25,38 , and $70 \mathrm{~mm}$, and water cement ratios of $0.4,0.5$, and 0.6 were used. Table 1 shows typical values of the oxygen and chloride concentrations for each boundary condition. The oxygen and chloride diffusion coefficients are highly dependent on concrete quality and can increase by orders of magnitude from good quality concrete to poor quality concrete (Neville 2000).

The concrete cover and bar diameters used are shown in Table 2. These were chosen to yield the same $k$ ratios as in the experimental specimens, but with dimensions close to those of full size structural components.

\section{Effect of Boundary Conditions}

Figures 8, 9 and 10 show the calculated corrosion current for the first 200 days after corrosion starts. The corrosion current decreases as the rust thickness increases. The decrease in the corrosion current continues over the duration of corrosion until cracking of the concrete.

The corrosion rates for boundary condition types 1 and 2 (BC1 and $\mathrm{BC} 2)$ are quite similar. In the model, the available oxygen controls the corrosion rate and in both cases the oxygen availability is the same as shown in Table 1. Nevertheless, the corrosion current is slightly higher for $\mathrm{BC} 2$ compared to $\mathrm{BC} 1$ due to the greater availability of water in the concrete pores for $\mathrm{BC} 2$. In the model, only dissolved oxygen in water can contribute to the corrosion process (see Equation 10). The concrete water content resulting from equilibrium with the outside humidity (Bazant and Thonguthai 1978, 1979 ) is lower for $\mathrm{BC} 1$ than for $\mathrm{BC} 2$ and therefore the corrosion current is correspondingly lower. For comparable concrete cover the corrosion current is almost 5\% higher in $\mathrm{BC} 2$ compared to $\mathrm{BC} 1$. The time to cracking of the concrete cover for $\mathrm{BC} 1$ and 
$\mathrm{BC} 2$ is shown in Figure 11. The 5\% increase in corrosion current from $\mathrm{BC} 1$ to $\mathrm{BC} 2$ decreases the time to cracking by $10 \%$ to $25 \%$. For BC3 (substructure submerged in water), the corrosion current is an order of magnitude smaller than for $\mathrm{BC} 1$ and $\mathrm{BC} 2$ because the oxygen availability is very limited. This can increase the life of the structure by more than an order of magnitude. The cracking time for $\mathrm{BC} 3$ was not calculated since it was computationally very expensive and after more than 25 years the concrete cover did not crack even for the smallest $k=3$.

\section{Effect of Concrete Quality}

The concrete quality is controlled mainly by the w/c ratio. Concrete with a high w/c ratio has high porosity and diffusion of oxygen through the concrete cover is highly dependent on the concrete porosity (Neville 2000). As Figure 8, 9 and 10 show, decreasing the w/c ratio from 0.6 to 0.5 reduces the corrosion current by about $45 \%$, and decreasing the w/c ratio from 0.5 to 0.4 reduces it again by about another $45 \%$ for all the cases. Also decreasing the $\mathrm{w} / \mathrm{c}$ ratio by 0.1 increases the concrete strength by almost 6,895 to $10,342 \mathrm{kPa}$ (1000 to $1500 \mathrm{psi}$ ) (Neville 2000). As shown in Figure 11, decreasing the w/c ratio by 0.1 increases the cracking time by 1.5 to 3 times (depending on other factors) due to the combination of increased concrete strength and decreased porosity.

\section{Effect of Concrete Cover}

Although the concrete cover has a significant effect on the time for depassivation and initiation of corrosion, it does not seem to have a significant effect on the corrosion rate. The corrosion rate is about the same for all three $k$ ratios considered. 
After concrete quality, the next most important factor that affects the cracking time of the concrete cover is the $k$ factor. A larger cover increases the time for chloride diffusion. However, a larger $k$ value provides more mechanical resistance to cracking and thereby significantly increases the cracking time as shown in Figure 12. Increasing $k$ from 3 to 4 approximately doubles the cracking time, and increasing it from 4 to 6 approximately doubles it yet again.

\section{Rust Thickness Growth}

Several models such as linear, parabolic, and more complicated power laws have been proposed for the growth of rust with time (Tomoshov 1966) and may be expressed in the general form:

$$
y^{n}=k t
$$

where $y$ is the rust thickness, $t$ is time, and $n$ is an empirical constant.

Here we present results of the rust thickness growth over time based on the holistic electrochemical-mechanistic model presented herein and compare them to the empirical model in Equation 32.

\section{Rust Build-Up}

Figure 13 shows the results of the rust growth predicted by the electrochemical model over time for different $\mathrm{w} / \mathrm{c}$ ratios. In the model the rate of rust growth is independent of the concrete cover and is affected only by the boundary condition and w/c ratio. 
Although the electrochemical model is more complex than the simple empirical equation, the end results are very similar as shown in Figure 13 if the parameters $n$ and $k$ in Equation 32 are properly calibrated. However, the more complex model is based on material and environmental characteristics and can be used in a variety of situations without the need for calibration.

\section{Rust Flow into Pores}

One of the factors that affect the time to cracking of the concrete cover is the flow of rust products into the concrete pores. The process of rust flow has not been effectively modeled in the past. The rust products can only flow a certain distance from the steel bar before cracking of the concrete. The calculated distance according to our model can be between 2 to $15 \mathrm{~mm}$, depending on many factors such as the w/c ratio and boundary conditions.

The flow of rust products into the concrete pores decreases the amount of accumulated pressure and increases the time to cracking. Figure 14 shows the reduction in accumulated pressure for different cases. The loss in pressure is $1 \%$ to $2 \%$ for a w/c ratio of 0.4 , and $5 \%$ to $17 \%$ for the w/c ratios of 0.5 and 0.6 . Concrete with a high w/c ratio has higher porosity and therefore more rust can flow into it. The amount of rust that flows into the surrounding concrete is highest for $\mathrm{BC} 1$ due to the lower degree of saturation, and similar but lower for $\mathrm{BC} 2$ and $\mathrm{BC} 3$.

\section{CONCLUSIONS}

A holistic electrochemical-mechanistic model is developed for the corrosion of reinforcing steel in concrete in the presence of chloride ions, and the time to cracking of the concrete cover. The limiting corrosion current is modeled based on the cathodic 
limiting reaction and oxygen diffusion. The model was calibrated using accelerated corrosion testing under a microscope to establish the relationship between rust thickness and the time to cracking of the concrete cover. In the constant current test, the accumulated rust thickness varied approximately linearly with time until cracking of the concrete cover.

The developed model was used to predict the corrosion current and the time to cracking of the cover for three classes of concrete components in bridges. The corrosion current was calculated for different boundary conditions, concrete properties and concrete cover. The concrete cover did not have a significant effect on the corrosion current. The two main factors that influence the corrosion current are the boundary conditions and the concrete quality. When the $\mathrm{w} / \mathrm{c}$ ratio is increased, the concrete quality decreases, the permeability of concrete increases, the diffusion of oxygen and water into the concrete increase, and consequently the corrosion current increases.

The time to cracking of the concrete cover is influenced by the corrosion rate, the concrete quality and the cover. Increasing the w/c ratio by 0.1 decreases the time to cracking by 1.5 to 3 times depending on other factors.

Concrete bridge components in the splash zone have the highest availability of water, chloride and oxygen, corrode about 5\% faster than superstructure components, and the life of the former can be $10 \%$ to $25 \%$ less than the latter. Due to the lack of oxygen, the corrosion rate in submerged components is an order of magnitude lower than components exposed to air tremendously lengthening their life. Increasing the concrete cover from 38 to $51 \mathrm{~mm}$ (1.5 to $2 \mathrm{in}$.) can double the time to cracking. Increasing the cover further from 51 to $76 \mathrm{~mm}$ ( 2 to $3 \mathrm{in}$.) further doubles the time to cracking. 
Using good quality concrete with a low w/c ratio and the largest affordable cover are the easiest ways to protect concrete structures from corrosion damage.

\section{REFERENCES}

Ann, K. Y., Song, H. W. (2007). "Chloride threshold level for corrosion of steel in concrete.” Journal of Corrosion Science, 49, 4113-4133.

Alonso, C. M., Castrllote, C., and Andrade (2002). "Chloride threshold dependence of pitting potential of reinforcements." Journal of Electrochimica Acta, 47, 3469-3481.

Austin, S. A., Lyons, R., and lng, M. J. (2004). "Electrochemical behavior of steelreinforced concrete during accelerated corrosion testing." Journal of Corrosion Science, 60, 203-212.

Bhagava, K., Ghosh, A. K., Mori, Y., and Ramanujam (2005). "Modeling of time to corrosion-induced cover cracking in reinforced concrete structures." Journal of Cement and Concrete Research, 35, 2203-2218.

Bazant, Z. P., Najjar, L. J. (1972). "Nonlinear water diffusion of nonsaturated concrete.” Materiaux et Constructions, 5 (25).

Bazant, Z. P. (1979). "Physical model for steel corrosion in sea structure-application." Journal of Structural Division, ASCE, 105, 1155-1166.

Bazant, Z., and Thonguthai, W. (1979). "Pore pressure in heated concrete walls: theoretical prediction." Magazine of Concrete Research, 31(107), 67-76.

Bazant, Z., and Thonguthai, W. (1978). "Pore pressure and drying of concrete at high temperature." Journal of the Engineering Mechanics Division, ASCE, 104, 10581080. 
Castellote, M., Alonso, C., Andrade, C., Chadbourn, G. A., and Page, C. L. (2001). "Oxygen and chloride diffusion in cement pastes as a validation of chloride diffusion coefficients obtained by steady-state migration test." Cement and Concrete Research, $31,621-625$.

Caré, S., Nguyen, Q. T., Hostis, V. L., and, Berthaud, Y. (2008). “Mechanical properties of the rust layer induced by impressed current method in reinforced mortar." Cement \& Concrete Research 38, 1079-1091.

Coussy, O., Dangla, P., Lassabatere, T., and Baroghel-Bouny, V. (2004). “The equivalent pore pressure and the swelling and shrinkage of cement-based materials." Materials and Structures / Concrete Science and Engineering, 37, 15-20.

Du, Y. G., Chan, A. H. C., and Clark, L. A (2006). "Finite element analysis of the effects of radial expansion of corroded reinforcement." Computers and Structures, 84(1314), 917-929.

El Maaddawy, T., Chahrou, A., and Soudki, K. (2006). "Effect of fiber reinforced polymer wraps on corrosion activity and concrete cracking in chloride-contaminated concrete cylinders. ” Journal of Composites for Construction, ASCE, 10(2), 139-147.

El Maaddawy T., and Soudki, K., (2007). "A model for prediction of time from corrosion initiation to corrosion cracking." Cement \& Concrete Composites, 29, 168-175.

Glass, G. K., Buenfeld, N. R. (2000). "The influence of chloride binding on the chloride induced corrosion risk in reinforced concrete." Journal of Corrosion Science, 42, 329-344.

Hausmann, D. A. (1967). "Steel corrosion in concrete - how does it occur." Journal of Materials Protection, 6(11). 
Huet, B., L'hostis, V. L., Santarini, G., Feron, G. and Idrissi, H. (2007). "Steel corrosion in concrete: deterministic modelling of cathodic reaction as a function of water saturation degree", Corrosion Science, 49, 1918-1932.

Jones, D. A. (1992). Principles and prevention of corrosion. MacMillan, New York.

Liang, M. T., Jin, W. L., Yang, R. J., and Huang, N. (2005). "Predeterminate model of corrosion rate of steel in concrete." Cement and Concrete Research, 35, 1827-1833.

Liu, Y. (1996). "Modeling the time to corrosion cracking of the cover concrete in chloride contaminated reinforced concrete structure." Ph.D. Dissertation, Virginia Polytechnic Instituted, Blackburg, VA.

Kassir, K. M. and Ghosn, M. (2002). "Chloride-induced corrosion of reinforced concrete bridge decks," Cement and Concrete Research, 32, 139-143.

Martys, S. N. Torquato, S., and Bentz D. P. (1994). "Universal scaling of fluid permeability for sphere stacking." Physical Review E, 50(1), 403-408.

MacGregor, J., and Wight, K. J. (1997). Reinforced concrete: mechanics and design. Prentice-Hall, New Jersey.

Metha, P. K. (1993). Concrete structure, properties and materials. Prentice-Hall, New Jersey.

Mindess, S. Young, J. F., and Darwin, D. (2003). Concrete, Second Edition, Prentice Hall, New Jersey.

Monlouis, J. P., Verdier, J., and Perrin, B. (2007). "Predication of the relative permeability to gas flow of cement-based materials." Journal of Cement and Concrete Research, 34, 737-744.

Neville, A. M. (2000). Properties of concrete. Fourth Edition, Prentice-Hall, New Jersey. 
Nossoni, G. (2010). "Holistic electrochemical and mechanistic modeling of corrosioninduced cracking in concrete structures." Ph.D. Dissertation, Michigan State University, East Lansing, Michigan.

Nossoni, G., Harichandran R. S., and Barton, S. C. (2011). "Chloride-induced corrosion of reinforcing steel in concrete: electrochemical modeling of initial corrosion rate." Corrosion 2011 Conference, NACE, Texas, USA.

Newhouse, C. D., and Weyers, R. E. (1996). "Modeling the measured time to cracking" Corrosion Activity of Reinforced Concrete Structure, In ASTM STP 1276, 3-21.

Newhouse, C. D. (1993). "Corrosion rates and the time to cracking model for critically contaminated reinforced concrete structures." Master of Science Thesis, Virginia Polytechnic Instituted, Blackburg, VA.

Palle, T. C. (2002). "Deterioration of concrete structures.” Proceedings, First Pantazopoulou, and K. Papoulia, "Modeling Cover-Cracking Due to Reinforcement Corrosion in RC Structures.” Journal of Engineering Mechanics, ASCE, Vol. 127, No. 4, pp.342-451 (2001).

Sarin, P., Snoeyink, V. L., Lytle, D. A., and Kriven, W. M. (2004). “Iron corrosion scale: model for scale growth, iron release, and colored water formation." Journal of Environmental Engineering, ASCE, 130(4), 364-373.

Shah, S. P., and Swart, S. E. (1987). Fracture of concrete and rocks. Springer-Verlag, New York.

Thoft-Christensen, P. (2002) "Deterioration of concrete structures.” Proceedings, First International Conference on Bridge Maintenance, Safety and Management, IABMAS, Barcelona, July 14-17, 16 pp. 
Tomoshov, N. D. (1966). Theory of corrosion and protection of metals. McMillan Co., New York.

Van Genuchten, M. Th. (1980). "A close form equation for predicting the hydraulic conductivity of unsaturated soils." Journal of the Soil Sci. Soc. Am., 44(5), 892-898.

Xi, Y., Willam, K., and Frangopol, D. M. (2000). "Multiscale modeling of interactive diffusion processes in concrete." Journal of Engineering Mechanics, ASCE, 126(3), $258-265$. 


\section{List of Tables}

Table 1: Different Concentration Boundary Conditions $\left(\mathrm{gr} / \mathrm{cm}^{3}\right)$

Table 2: Geometry

\section{List of Figures}

Figure 1: Corrosion scale model (adopted from Jones 1992, Sarin et al. 2004)

Figure 2: Oxygen diffusion path

Figure 3: Finite element analysis for calibrating the model

Figure 4: Test Specimens

Figure 5: Test set up under microscope

Figure 6: Images of rust thickness under the microscope for specimens with $k=6$

Figure 7: Rust thickness over time for specimens with $k=3,4$, and 6

Figure 8: Corrosion current for $\mathrm{BC} 1$

Figure 9: Corrosion current for $\mathrm{BC} 2$

Figure 10: Corrosion current for $\mathrm{BC} 3$

Figure 11: Effect of water cement ratio on concrete cracking time: (a) BC1 and (b) BC2

Figure 12: Effect of concrete cover on cracking time (a) BC1 and (b) BC2

Figure 13: Comparison between model and Equation 32

Figure 14: Reduction in pressure as a percentage of the final pressure 
Table 1: Different Concentration Boundary Conditions $\left(\mathrm{g} / \mathrm{cm}^{3}\right)$

\begin{tabular}{c||cc}
\hline \hline $\begin{array}{c}\text { Boundary } \\
\text { Condition }\end{array}$ & $\begin{array}{c}\text { Oxygen } \\
\text { Concentration }\end{array}$ & $\begin{array}{c}\text { Chloride } \\
\text { Concentration }\end{array}$ \\
\hline \hline Type 1 & $3.04 \times 10^{-4}$ & $1.495 \times 10^{-3}$ \\
Type 2 & $3.04 \times 10^{-4}$ & $1.301 \times 10^{-2}$ \\
Type 3 & $7.0 \times 10^{-7}$ & $1.91 \times 10^{-2}$ \\
\hline \hline
\end{tabular}

Table 2: Geometry

\begin{tabular}{c||cc}
\hline \hline Ratio $(k)$ & $\begin{array}{c}D \text { (Concrete Cover) } \\
\text { mm (in.) }\end{array}$ & $\begin{array}{c}d \text { (Bar Diameter) } \\
\text { mm (in.) }\end{array}$ \\
\hline \hline 3 & $25(1.0)$ & $25(1.0)$ \\
4 & $38(1.5)$ & $25(1.0)$ \\
6 & $63(2.5)$ & $25(1.0)$ \\
\hline \hline
\end{tabular}




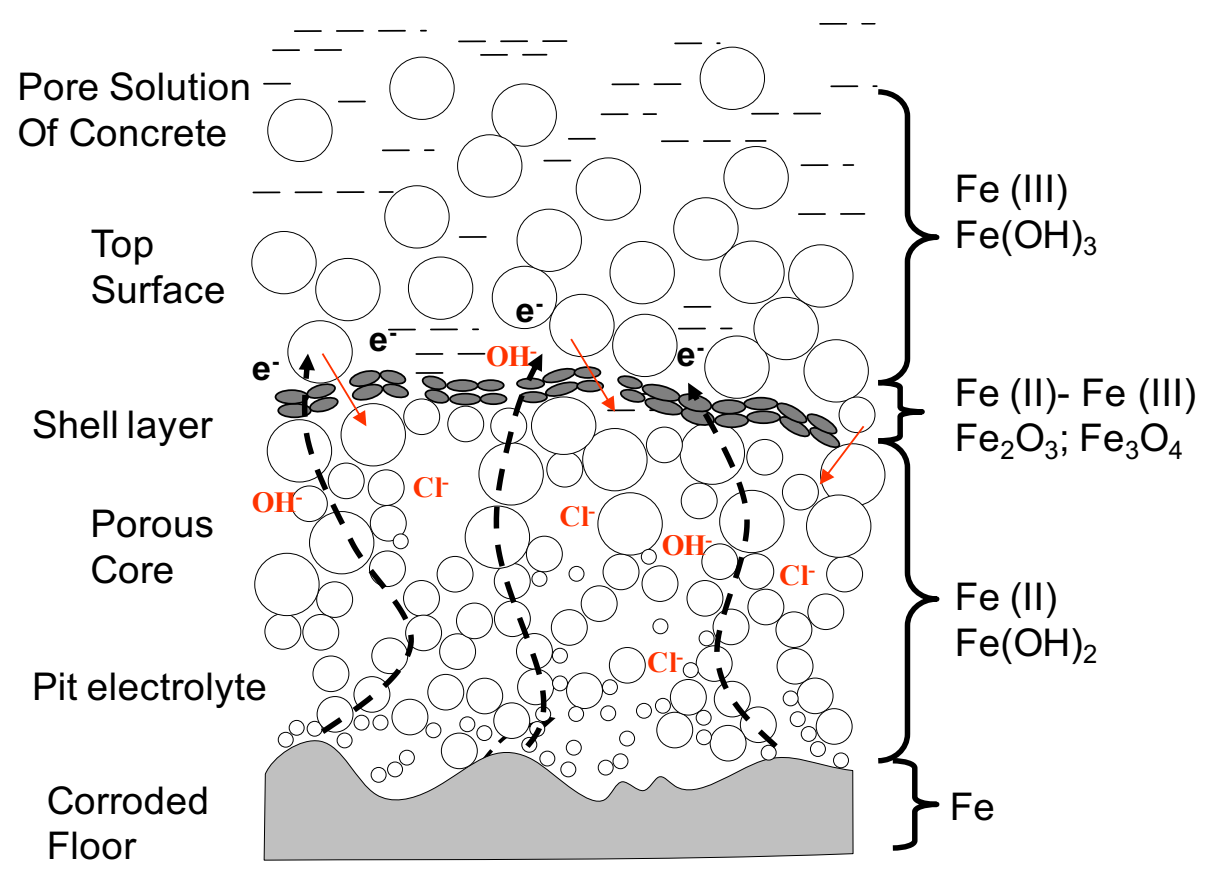

Figure 1: Corrosion scale model (adopted from Jones 1992, Sarin et al. 2004)

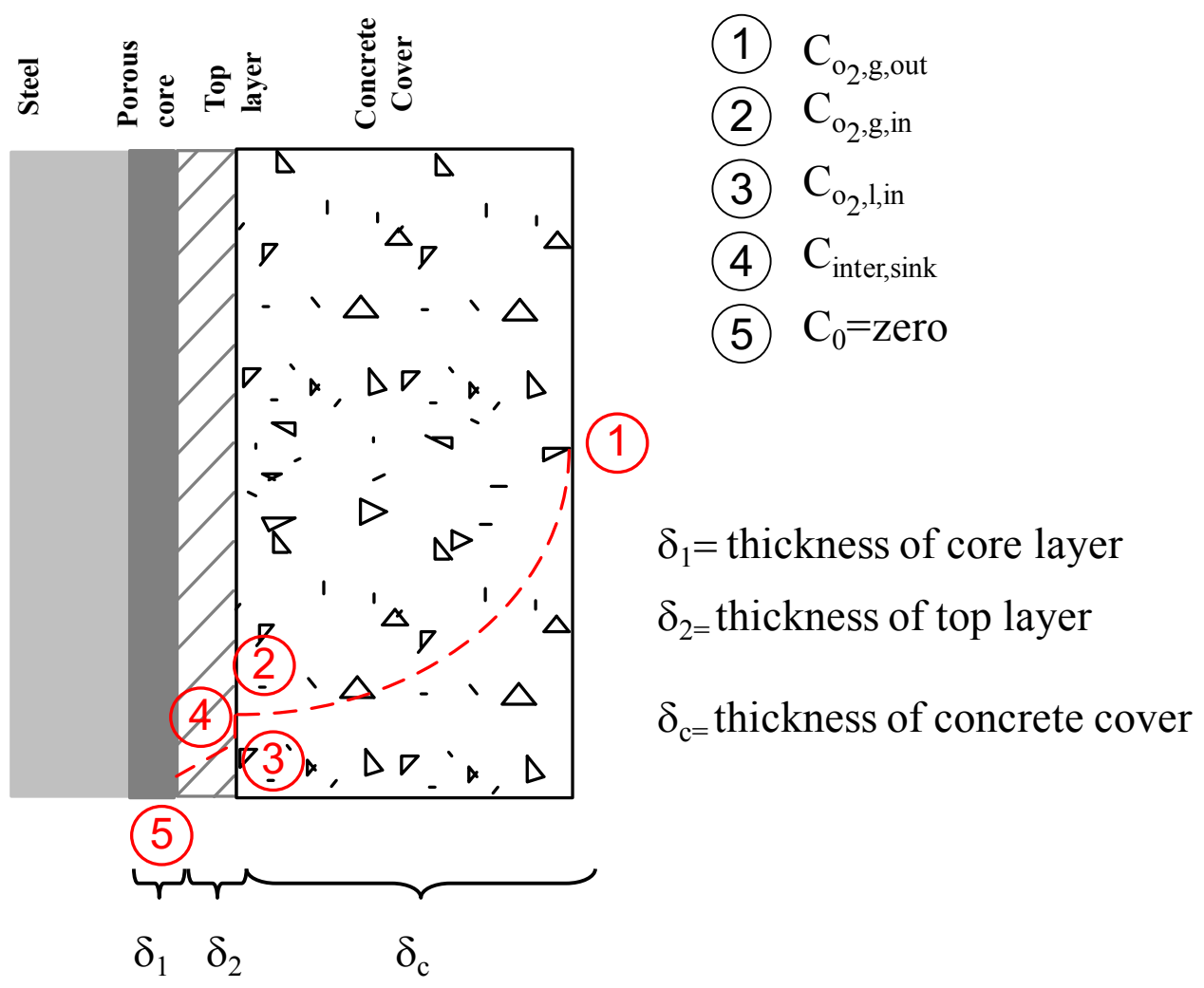

Figure 2: Oxygen diffusion path 


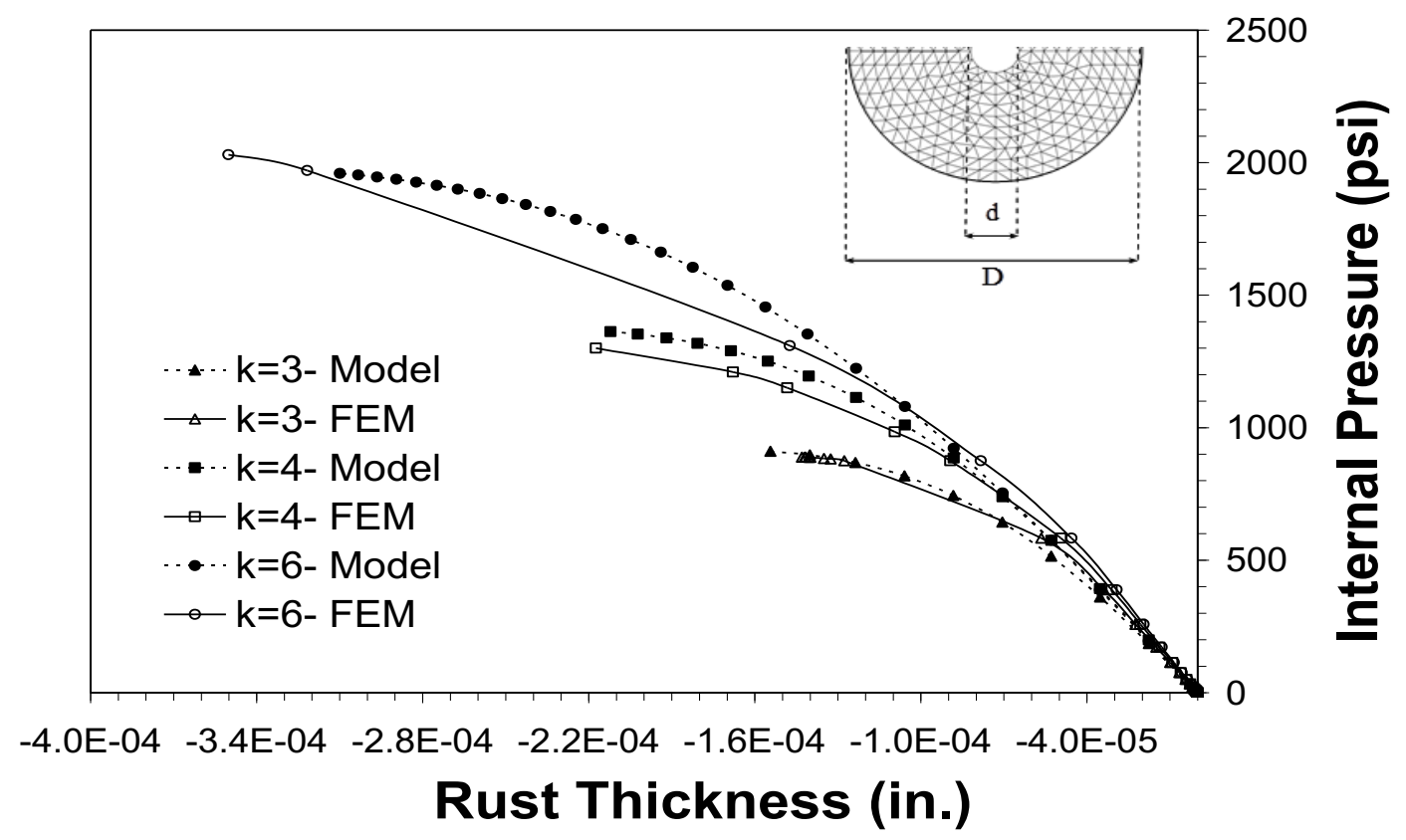

Figure 3: Finite element analysis for calibrating the model 

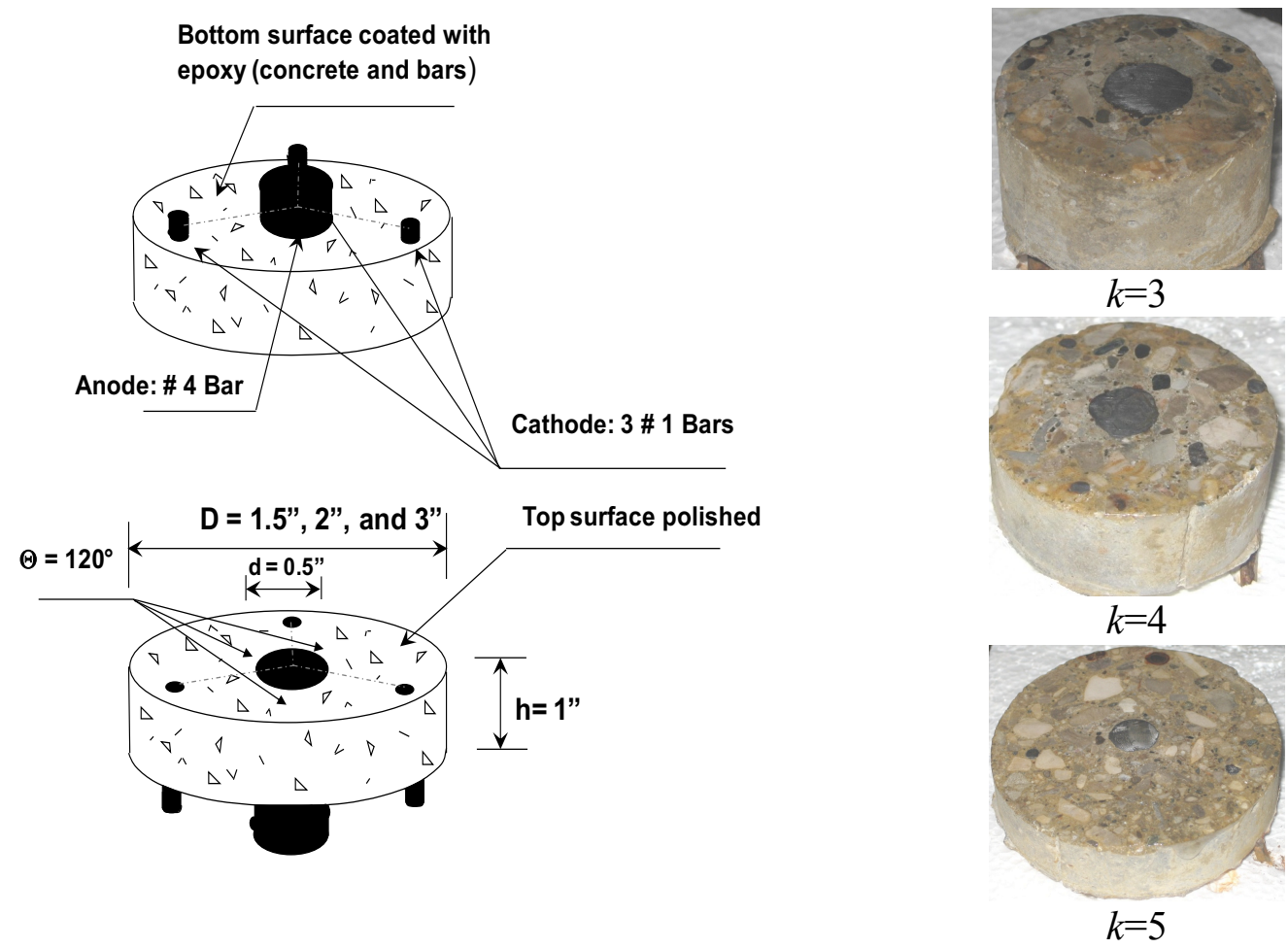

Figure 4: Test Specimens
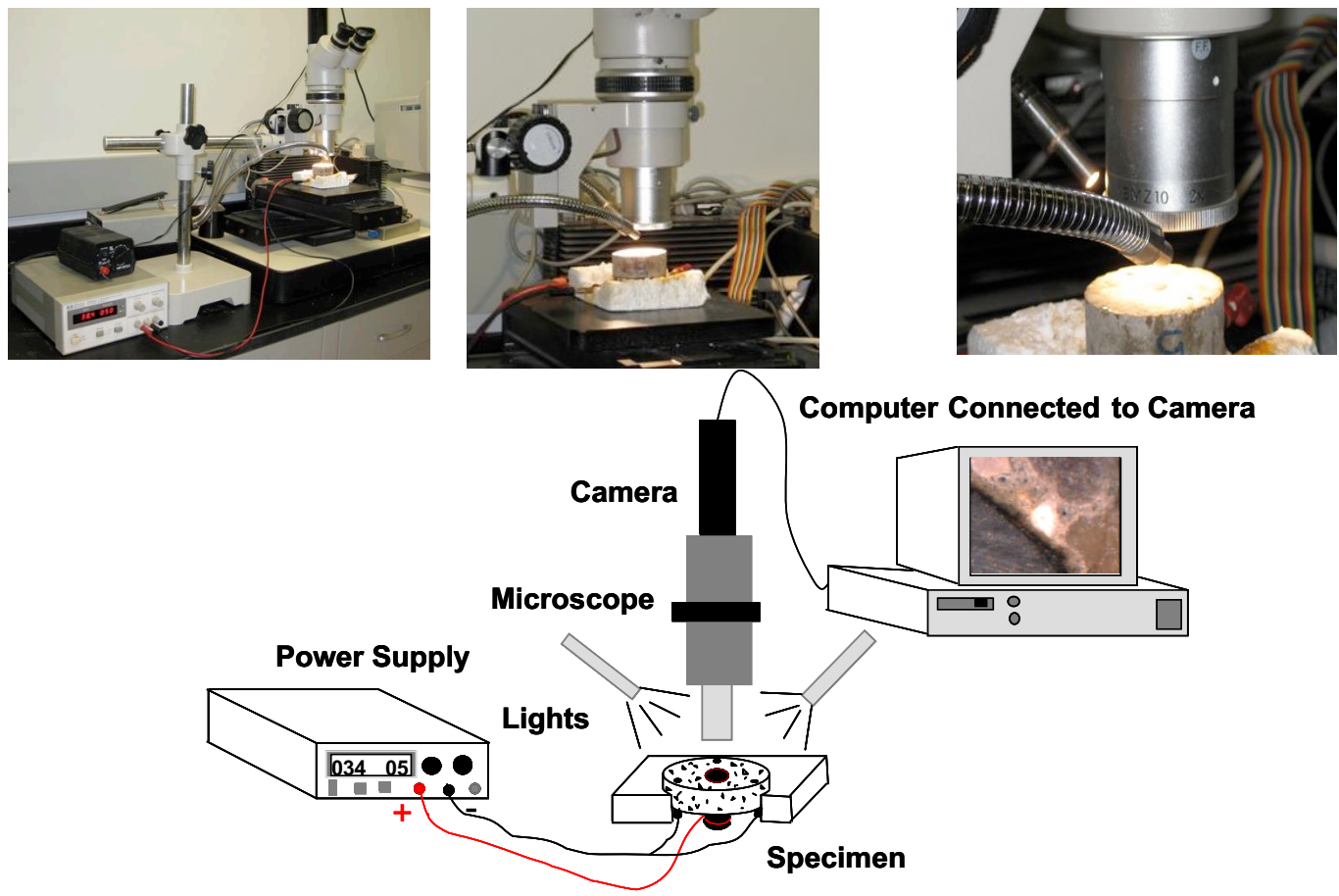

Figure 5: Test set up under microscope 


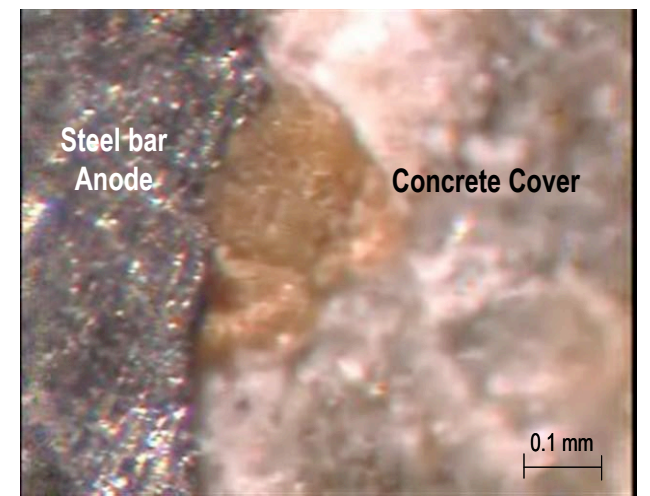

(a) $t=0$ min

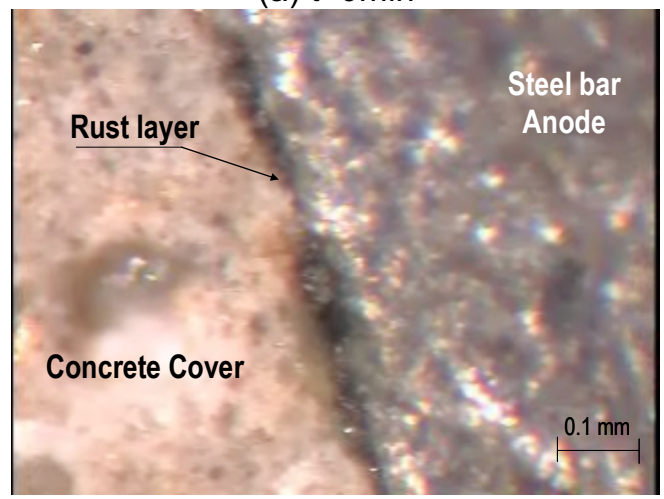

(c) $t=70 \mathrm{~min}$

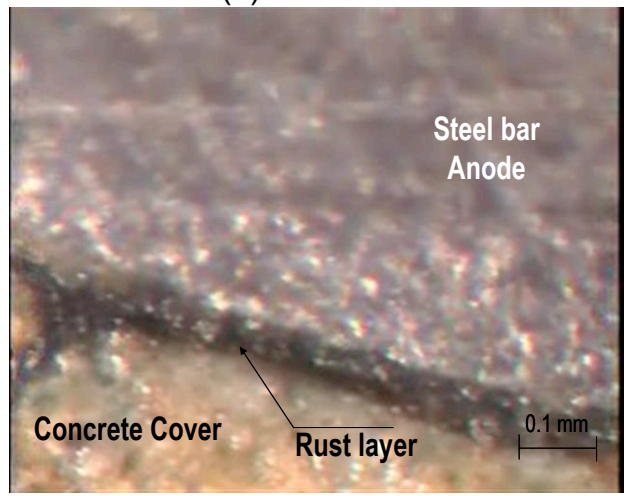

(e) t=115 min-Cracking

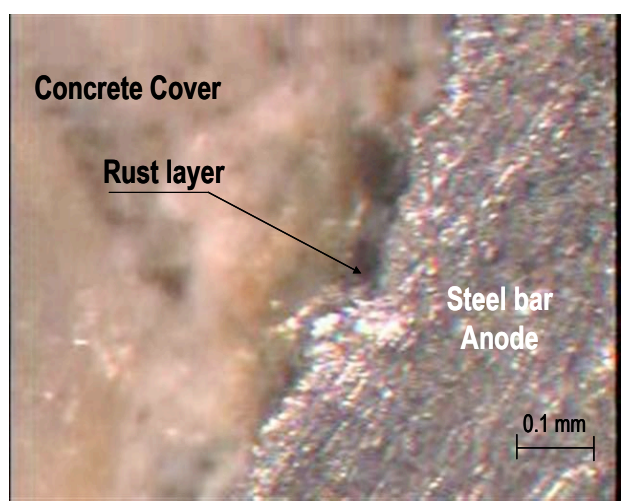

(b) t=35 min

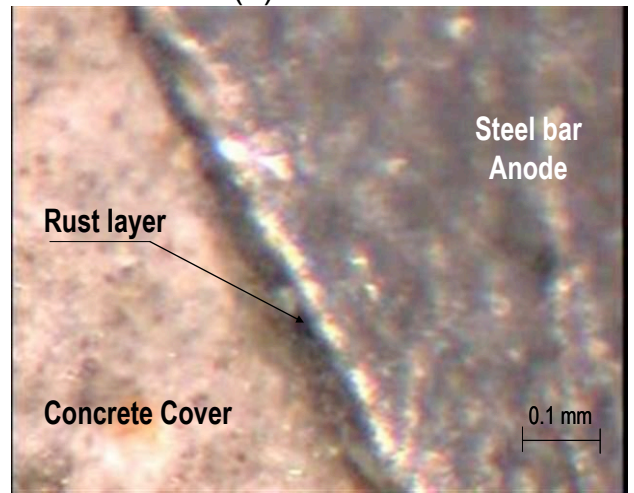

(d) t=90 min-Cracking

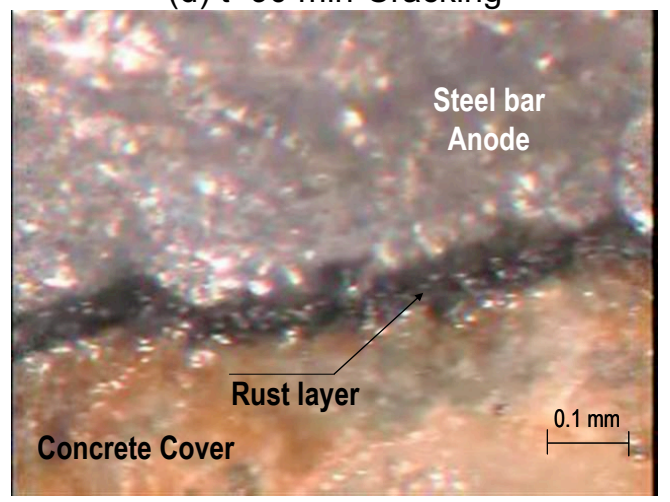

(f) t=130 min-Cracking

Figure 6: Images of rust thickness under the microscope for specimens with $k=6$ 


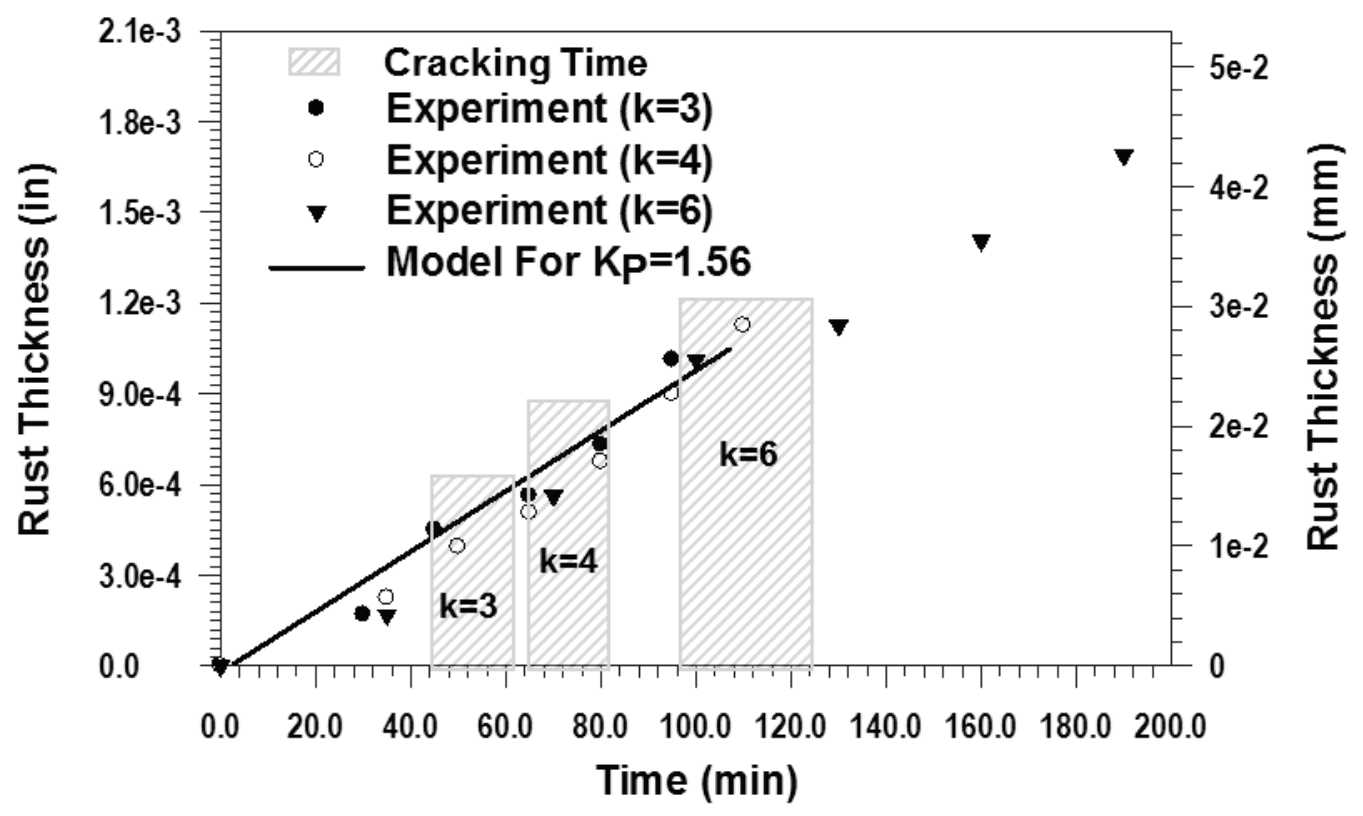

Figure 7: Rust thickness over time for specimens with $k=3$, 4, and 6

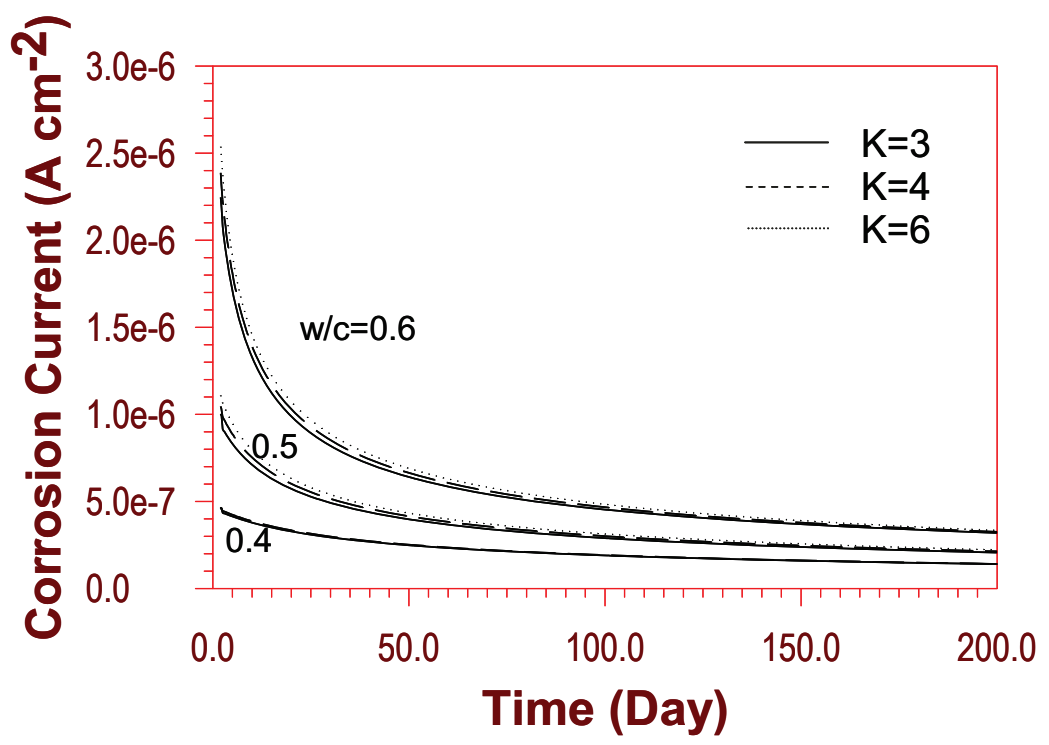

Figure 8: Corrosion current for $\mathrm{BC} 1$ 


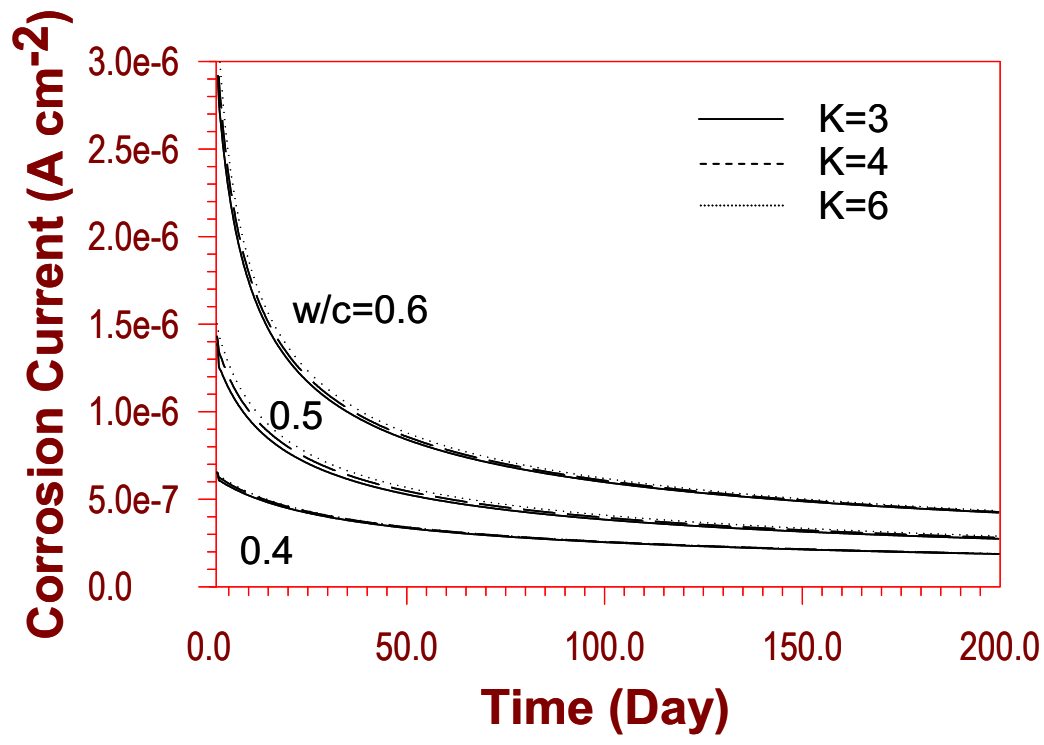

Figure 9: Corrosion current for $\mathrm{BC} 2$

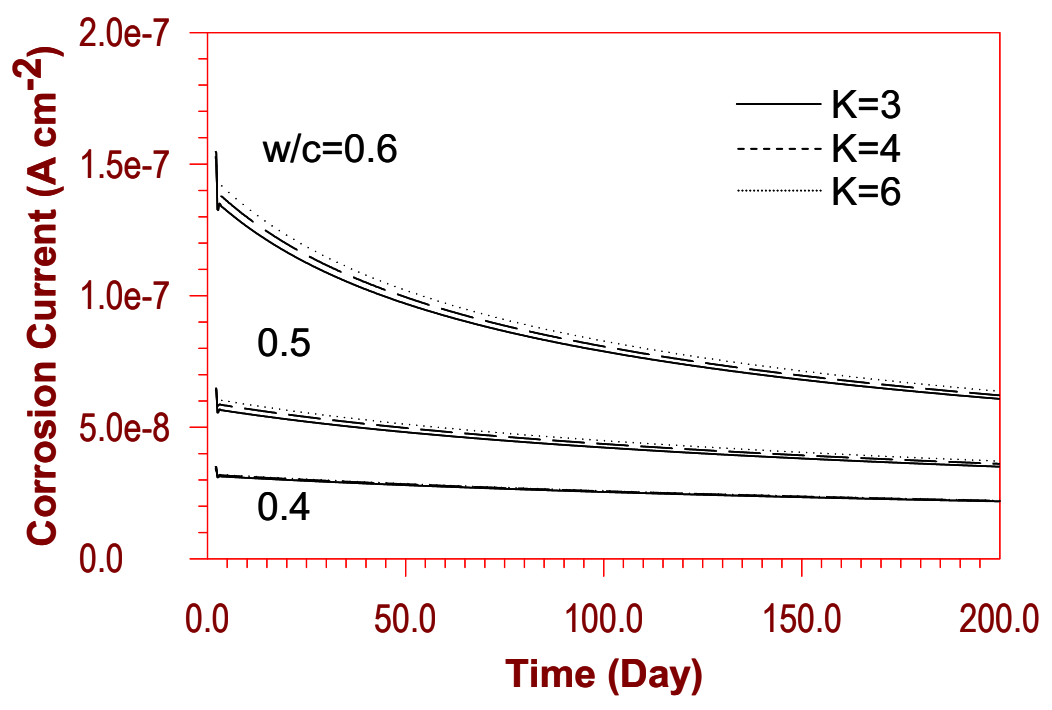

Figure 10: Corrosion current for $\mathrm{BC} 3$ 


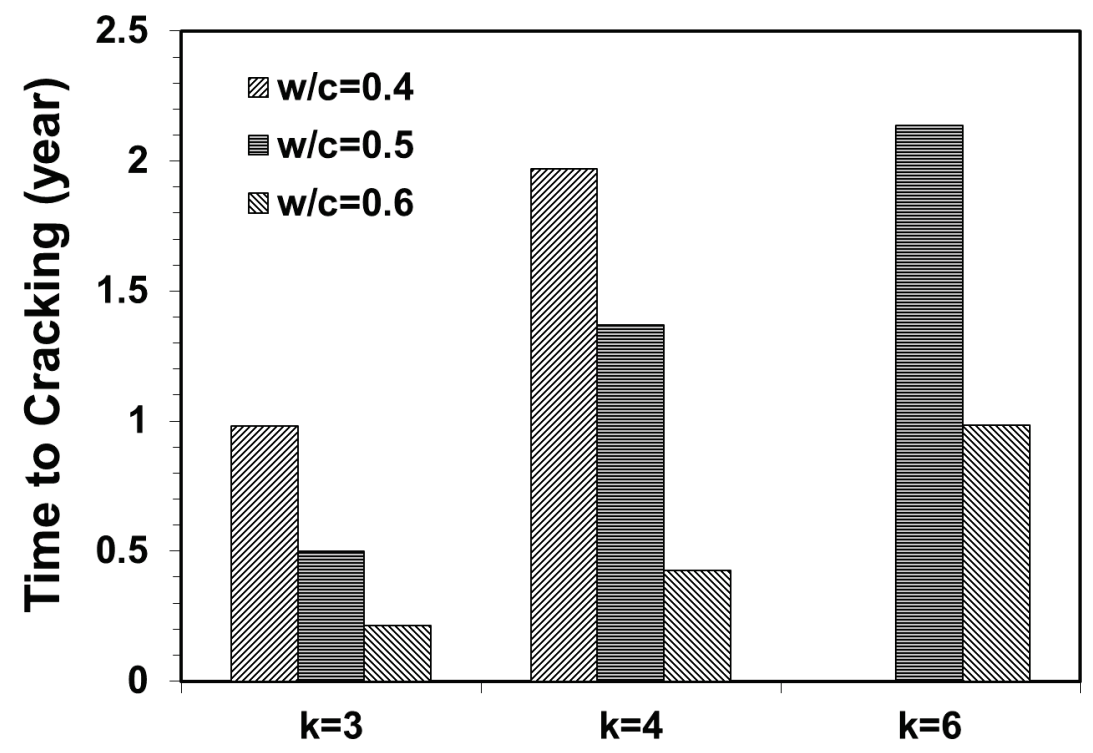

(a)

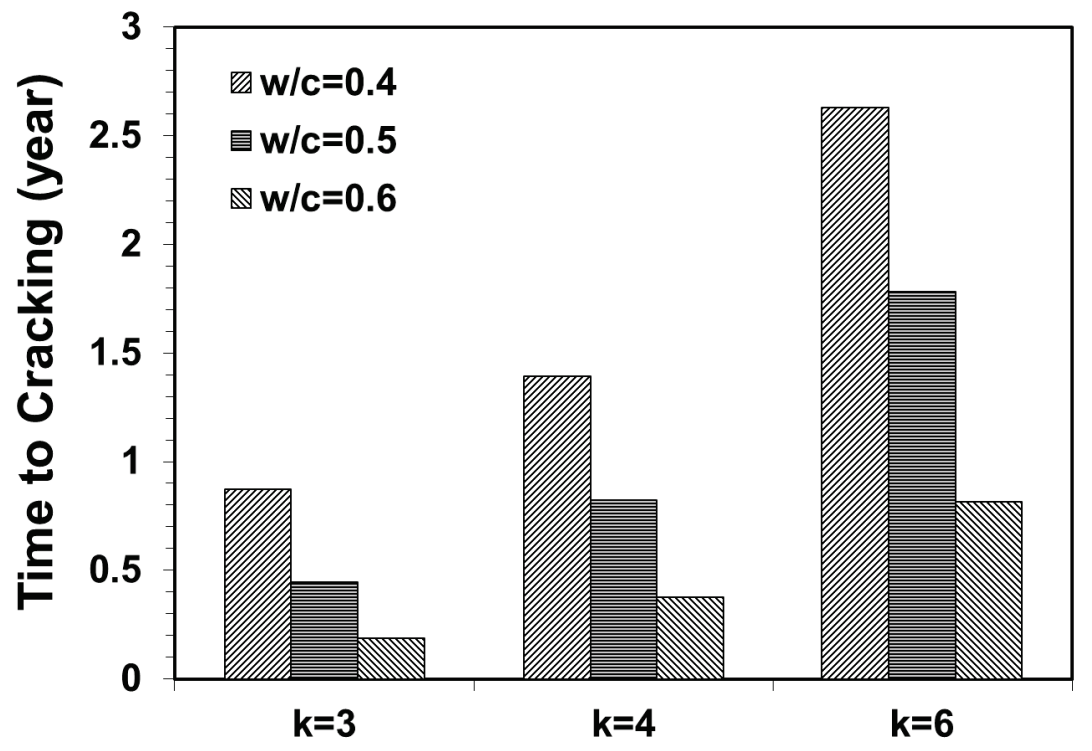

(b)

Figure 11: Effect of water cement ratio on concrete cracking time: (a) BC1 and (b) BC2 


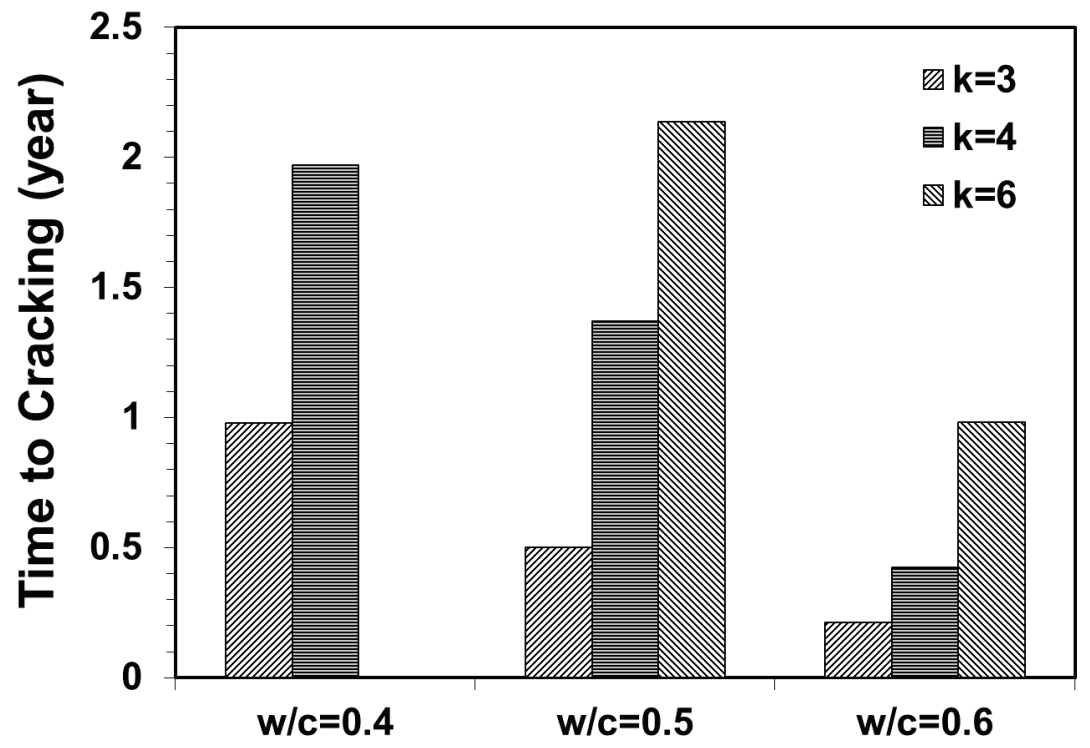

(a)

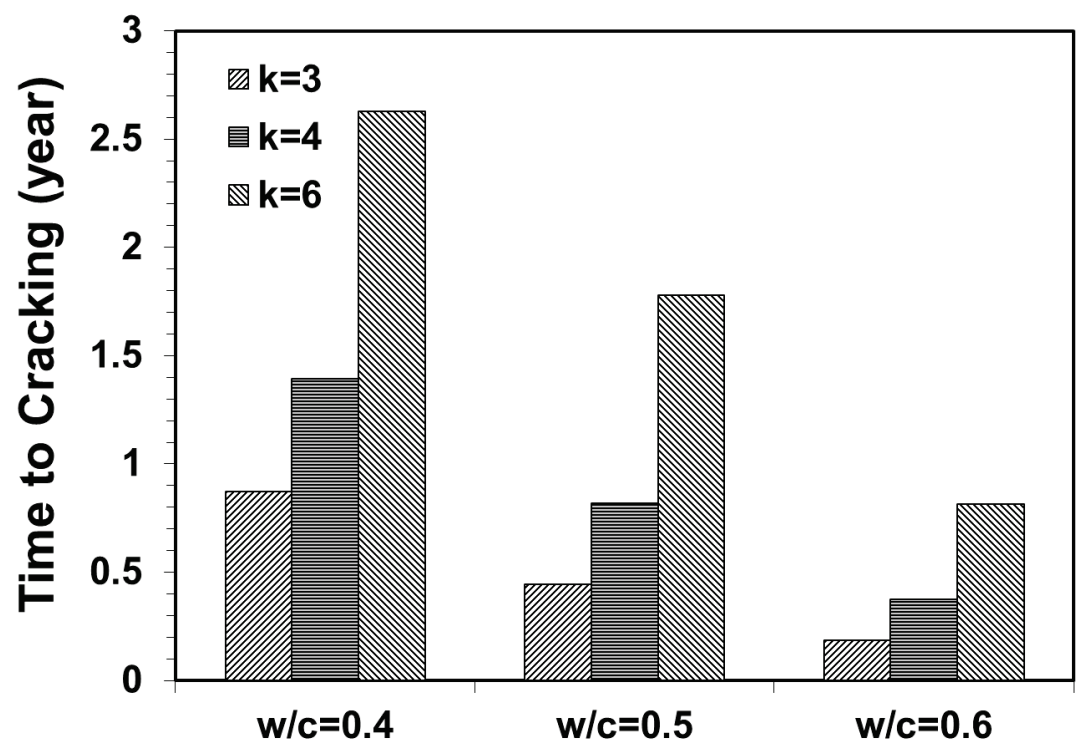

(b)

Figure 12: Effect of concrete cover on cracking time (a) $\mathrm{BC} 1$ and (b) $\mathrm{BC} 2$ 


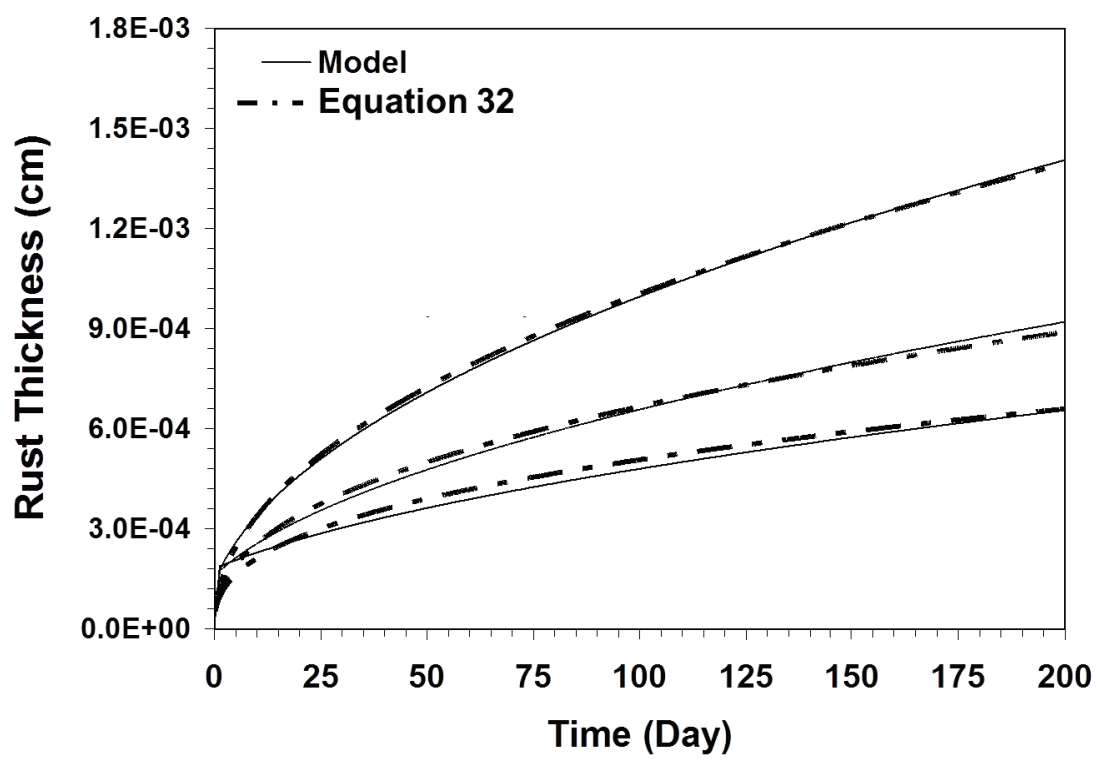

Figure 13: Comparison between model and equation 32

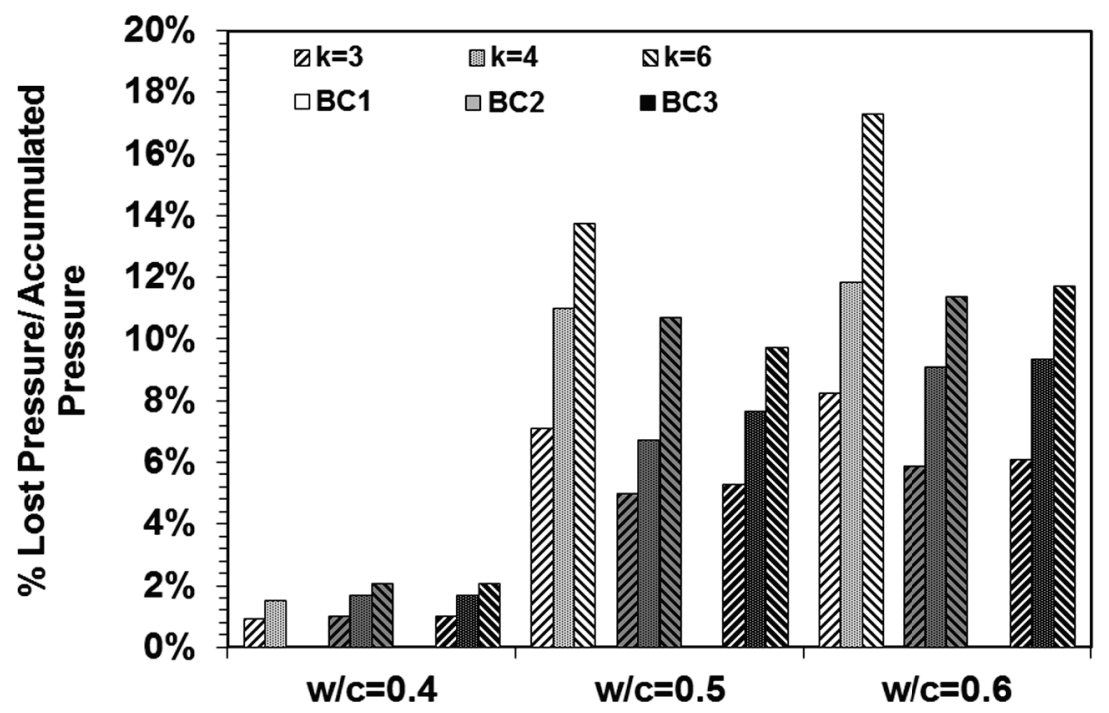

Figure 14: Reduction in pressure as a percentage of the final pressure 